\title{
Bacterial communities in the gastrointestinal tract segments of helminth-resistant and helminth- susceptible sheep
}

Erwin A. Paz ( $\nabla$ erwin.pazmunoz@uwa.edu.au )

The University of Western Australia https://orcid.org/0000-0003-4093-7415

\section{Eng Guan Chua}

The University of Western Australia

Johan C. Greeff

: Government of Western Australia Department of Primary Industries and Regional Development

\section{Shamshad Ul Hassan}

The University of Western Australia

\section{Dieter G. Palmer}

: Government of Western Australia Department of Primary Industries and Regional Development

\section{Shimin Liu}

The University of Western Australia

\section{Binit Lamichhane}

The University of Western Australia

\section{Néstor Sepúlveda}

Universidad de La Frontera

Chunhua Liu

Nanjing Agricultural University

\section{Chin Yen Tay}

The University of Western Australia

\section{Graeme B. Martin}

The University of Western Australia

\section{Research Article}

Keywords: Sheep, microbiome, helminth, faecal-egg count, 16S rRNA gene sequencing, nematode

Posted Date: May 13th, 2021

DOI: https://doi.org/10.21203/rs.3.rs-497695/v1 
License: (c) (i) This work is licensed under a Creative Commons Attribution 4.0 International License. Read Full License

Version of Record: A version of this preprint was published at Animal Microbiome on March 14th, 2022. See the published version at https://doi.org/10.1186/s42523-022-00172-1. 


\section{Abstract \\ Background}

Helminth parasitism is a world-wide problem in livestock industries, with major impacts on health, welfare and productivity. It has been the subject of decades of research, but little attention has been paid to the role of the gut microbiota in the responses to infection. The present study characterized the microbiome along the gastro-intestinal tract (GIT) of sheep and tested whether it had been affected by three decades of breeding for resistance to helminth infection. Australian Sheep Breeding Values (ASBVs) for faecal egg count (FEC) were used to select the 10 most worm-susceptible (High-FEC) and 10 most worm-resistant (Low-FEC) animals. DNA was extracted and sequenced for $16 \mathrm{~S}$ rRNA gene from faeces and from the lumen of the rumen, abomasum, duodenum, jejunum, ileum, caecum, and colon.

\section{Results}

The most frequent genera identified along the GIT were Eubacterium, Oscillibacter, and Ruminococcus. Intersectoral-specialization zones were identified along the GIT, with the duodenum revealing major differences between the High-FEC (helminth-susceptible) and Low-FEC (helminth-resistant) animals in values for Alpha and Beta diversity. The High-FEC and Low-FEC sheep differed significantly for three phyla (Firmicutes, Elusimicrobia, Chloroflexi) and 11 genera. At other GIT sites, Firmicutes was the most abundant phylum followed by Bacteroidetes, and Proteobacteria presenting no major differences between High-FEC and Low-FEC.

\section{Conclusions}

The gastro-intestinal microbial profile varies widely between helminth-resistant and helminth-susceptible sheep. Each GIT section appears to supports a particular bacterial composition leading to inter-sectoral differences among the various microbial communities. The animal's duodenum creates the right environment which results in a more diverse and richness microbial population in the helminth-resistant sheep and suggests that this population favours bacterial genera that generally ferment carbohydrates. The energy metabolism of sheep is largely based on the production of volatile fatty acids (acetate, butyrate, propionate) in the rumen, raising the possibility that butyrate-producing bacteria in the duodenum of helminth-resistant sheep, modulate the host's metabolism and assist in the regulation of the parasite burden.

\section{Background}

Gastrointestinal helminth infection is a major cause of economic loss in sheep industries worldwide - for example, for Australia in 2015, Meat and Livestock Australia estimated an annual loss of AUD436 million [1]. In Western Australian sheep, the most common and important species are Teladorsagia circumcincta 
and Haemonchus contortus found in the abomasum and Trichostrongy/us colubriformis found in the small intestine $[2,3]$. Clinical signs associated with high levels of $T$. circumcincta and $T$. colubriformis infections, include loss of appetite, rapid weight loss and profuse watery diarrhoea, whereas $\mathrm{H}$. contortus can cause acute anaemia and hypoproteinaemia [4].

To mitigate helminth infection in their flocks, many farmers have resorted to frequent and intensive use of anthelmintic drugs, leading to the development of helminth populations that are resistant to one or more classes of parasiticide [5-7]. These problems have led to global efforts to genetically select sheep with natural resistance to helminth infection, using faecal egg count (FEC) as the phenotypic trait [8-10]. For example, the 'Rylington Merino' flock was established in 1988 and is currently the most worm-resistant Merino flock in Australia [11]. The level of resistance to helminths varies within and between sheep genotypes, reflecting genetic variation in the production of immunoglobulin A $(\lg A)$ specific to worm antigens, and thus variation in nematode survivability $[12,13]$. On the other hand, it was recently reported that the severity of $H$. contortus infection is related to the faecal microbiota in sheep, implying a supporting role for gut microbes in modulating the resistance of the host to infection [14]. Taken together, these studies suggest that, in the host, there is an intricate relationship between the immune system, the gut microbiome, and the response to helminth infection.

We tested whether the helminth burden affected the structure of the microbial communities in the various segments of the gastrointestinal tract (GIT), and whether variation in microbial communities would help explain differences between helminth-susceptible and helminth-resistant sheep. We used Merino sheep from two selection lines, helminth-resistant (Low-FEC; $n=10)$ and the helminth-susceptible (High-FEC; $n=$ 10), and compared microbial populations along the GIT tract using 16S rRNA gene sequencing.

\section{Results}

FEC differences between groupsThe FEC of each animal used in this study, from autumn through to spring, are presented in Table S1. The average cumulative values for the worm-susceptible (High-FEC) and worm-resistant (Low-FEC) sheep with are shown in Fig. 1. For the High-FEC group, the average was $1940 \pm 1120$ eggs/gram (mean \pm SD), more than 4 -fold greater than the average for the Low-FEC group $(410 \pm 423 ; p=0.018)$.

\section{Microbial diversity analysis}

The sequencing of the $16 \mathrm{~S} \mathrm{~V} 3-\mathrm{V} 4$ amplicons generated from the faecal material and the luminal samples from the eight GIT segments of the 20 sheep produced 13,100,180 raw reads, detailed in Table S2. Trimming, merging of overlapping paired-end reads, and filtering of sequences $<400 \mathrm{bp}$, reduced the number to $3,013,423$ sequences, ranging from 4,751 to 62,456 sequences per sample, and with an average sequence length of $449 \pm 4 \mathrm{bp}$. These sequences were converted into 328 OTUs at $97 \%$ sequence identity, revealing 14 phyla, 22 classes, 27 orders, 39 families and 59 genera after taxonomic classification. 
Alpha diversity analysis was used to estimate the species richness and bacterial diversity, and to compare values for these two variables among GIT segments within FEC group, and between FEC groups for each GIT segment. As shown in Table 1, richness and diversity differed significantly $(p<0.001)$ among GIT segments in both High-FEC and Low-FEC groups $(p<0.001)$. Further Tukey post-hoc multiple comparisons analysis between each segment is presented in the Table S3. The abomasum and rumen contained the richest and most diverse microbial populations, whereas the ileum had the lowest values for richness and shannon alpha diversity assessments. Interestingly, when the High-FEC and Low-FEC groups were compared within GIT segment, only in the duodenum was there a significantly greater microbial richness and diversity in the Low-FEC group than in the High-FEC group $(p<0.001)$. No significant differences in microbial diversity were observed between FEC groups in the other GIT segments.

Table 1

Alpha diversity analysis, based on species richness and Shannon diversity indices, for segments of the gastrointestinal tract in sheep that are helminth-susceptible (High-WEC) or helminth-resistant (Low-WEC). WEC: worm egg count; SD: standard deviation.

\begin{tabular}{|c|c|c|c|c|c|c|}
\hline \multirow[t]{2}{*}{ Segment } & \multicolumn{2}{|c|}{ Richness (mean \pm SD) } & \multirow[t]{2}{*}{$P$} & \multicolumn{2}{|c|}{ Shannon (mean $\pm S D)$} & \multirow[t]{2}{*}{$P$} \\
\hline & High FEC & Low FEC & & High FEC & Low FEC & \\
\hline Rumen & $139 \pm 14$ & $133 \pm 9$ & 0.265 & $5.7 \pm 0.4$ & $5.7 \pm 0.3$ & 0.591 \\
\hline Abomasum & $141 \pm 15$ & $142 \pm 10$ & 0.867 & $5.5 \pm 0.3$ & $5.6 \pm 0.4$ & 0.475 \\
\hline Duodenum & $103 \pm 24$ & $149 \pm 22$ & $<0.001$ & $4.6 \pm 0.4$ & $5.6 \pm 0.5$ & $<0.001$ \\
\hline Jejunum & $103 \pm 33$ & $113 \pm 27$ & 0.456 & $4.4 \pm 1.6$ & $5.0 \pm 1.1$ & 0.375 \\
\hline Ileum & $80 \pm 31$ & $104 \pm 41$ & 0.151 & $2.7 \pm 1.3$ & $3.9 \pm 1.7$ & 0.091 \\
\hline Caecum & $92 \pm 15$ & $98 \pm 16$ & 0.366 & $4.6 \pm 0.6$ & $4.6 \pm 0.4$ & 0.735 \\
\hline Colon & $103 \pm 26$ & $99 \pm 15$ & 0.679 & $4.7 \pm 0.6$ & $4.6 \pm 0.5$ & 0.844 \\
\hline Rectum & $109 \pm 23$ & $106 \pm 16$ & 0.796 & $4.9 \pm 0.6$ & $4.8 \pm 0.5$ & 0.694 \\
\hline$P$ & $<0.001$ & $<0.001$ & & $<0.001$ & $<0.001$ & \\
\hline
\end{tabular}

To avoid the potential confounding effect of FEC status, beta analysis was performed separately for the High-FEC and Low-FEC groups for each GIT segment. For the High-FEC group, our principal coordinates analysis (PCOA) based on Bray-Curtis distance metric (Fig. 2A) presented a plot with two tight clusters, one containing the rumen and abomasum samples, and the other containing the caecum, colon and faecal samples $\left(R^{2}=0.625, p<0.001\right)$. Samples from the duodenum, ileum and jejunum were more scattered, but generally remained close to each other. As shown in Fig. 2B, the Low-FEC group showed a similar clustering effect $\left(R^{2}=0.555, p<0.001\right)$, except for the duodenal samples which had shifted away 
from the ileum and jejunum towards rumen-abomasum, suggesting that the difference in worm burden could have affected the duodenal microbiota. This observation prompted another round of PCoA to estimate the difference in microbiota composition between the High-FEC and Low-FEC groups within each GIT segment. As expected, only the duodenal samples displayed a significant separation effect between groups (Fig. 2C: $\mathrm{R}^{2}=0.354, p=0.003$ ).

\section{Microbial profiles in individual GIT segments}

The microbial populations were analysed and compared within GIT segment between High-FEC and LowFEC groups. As shown in Fig. 3, some bacterial phyla and genera were found in at least $80 \%$ of both HighFEC and Low-FEC samples in any GIT segment. Eubacterium was the most common genus and was ubiquitous throughout the entire GIT. It was followed by Oscillibacter (present in no more than half of the jejunum and ileum samples) and Ruminococcus (slightly less common in the caecum and colon samples).

Regardless of FEC level, the large intestine, from which the caecum, colon and faecal samples were collected, shared 10 common bacterial genera which were present in low frequency, if not absent, in other GIT segments. These genera include Akkermansia, Alistipes, Anaeromassilibacillus, Anaerotignum, Bacteroides, Flavonifractor, Intestinimonas, Mailhella, Paraprevotella and Treponema. In the duodenum, it is worth noting that several genera differed by at least $50 \%$ between the High-FEC and Low-FEC samples, including Campylobacter, Saccharofermentans, Succiniclasticum, Elusimicrobium, Lachnoclostridium, Moryella, Stomatobaculum and Aminipila (Fig. 3).

At the abundance level, Firmicutes was the most abundant phylum across the all samples, with median relative values ranging from $24-66 \%$. Interestingly, in the ileum samples of the High-FEC group, the abundance of Proteobacteria was much higher at $57 \%$ than the values of $2 \%$ or less in the other samples (Fig. 4). At genus level, predominant in the rumen were Saccharofermentans, Pseudobutyrivibrio, Ruminococcus, Butyrivibrio, Succiniclasticum, Oscillibacter and Prevotella, comprising $15 \%$ of the total bacterial population in the High-FEC group and $20 \%$ in the Low-FEC group (Fig. 4). The abomasum had a similar microbial profile to the rumen, but with lower abundance values. Irrespective of the experimental group, in the caecum, colon and faeces, the three most abundant microbial groups, in order of abundance, were the Akkermansia, Bacteroides and Oscillibacter. On the other hand, the ileum samples contained a high abundance of Paeniclostridium (7-10\%) and Romboutsia (8-9\%) in both the High-FEC and Low-FEC groups.

\section{Duodenal phyla and genera in the High-FEC and Low-FEC groups}

As the duodenum was the only GIT segment that displayed a significant difference in microbial composition between the High-FEC and Low-FEC groups based on the PcoA analysis, we next performed a differential abundance analysis using the Wilcoxon rank-sum test to identify the distinguishing bacterial phyla and genera. As shown in Fig. 5A, the abundance levels of three bacterial phyla including 
Chloroflexi, Elusimicrobia and Firmicutes were shown to be significantly reduced among the High-FEC samples as compared to the Low-FEC counterparts ( $p<0.01$ for Chloroflexi; $p<0.001$ for Elusimicrobia and Firmicutes). Similarly, at the genus level, significant depletion of 11 bacterial genera were shown to occur among the High-FEC samples in comparison to the Low-FEC group, which include Aminipila, Coprococcus, Elusimicrobium, Flexilinea, Flintibacter, Lachnoclostridium, Moryella, Prevotella, Pseudobutyrivibrio, Sacchorofermentans and Succiniclasticum.

\section{Discussion}

In the duodenum, the bacterial populations differ considerably between the helminth-resistant and helminth-susceptible animals, perhaps helping to explain their different parasite burdens. Interestingly, there were no such differences between the groups in other sections of the GIT. The duodenum is the normal habitat for T. colubriformis in sheep [15] where this helminth is known to browse the mucosa and cause severe damage, including villus atrophy, crypt hyperplasia, and mucosal damage [16].

In the duodenum, alpha diversity values and bacterial richness were lower in the High-FEC group than in the Low-FEC group. In general ecological terms, greater diversity in a community indicates a more stable and favourable environment, suggesting that the duodenum of helminth-resistant sheep supports a better adapted microbiome which may make it difficult for the parasite to thrive. Thus in the helminthsusceptible sheep, can the lower diversity result in an unhealthy environment, i.e. different pH perhaps and/or a more inflamed duodenal mucosa, which will mean a more sustainable environment for the parasite. The lowest diversity values in the ileum indicates that the proliferation of micro-flora in the small intestine appears to be restricted, possibly by the high concentrations of bile, salts and digestive enzymes. The rumen-abomasum and large intestine (caecum, colon, faeces) maintained greater richness and diversity than the small intestine (duodenum, jejunum, ileum). Most nutrient digestion and absorption take place in the abomasum and small intestine [17], although some fermentation and absorption also occur in the caecum and colon [18].

Of the three phyla that dominated the duodenum of the helminth-resistant group, Firmicutes was the most abundant, in agreement with the observations by Wang et al [19] in small-tailed Han sheep. Indeed, the Firmicutes dominated the entire GIT, as seen in previous studies in ruminants [20,21]. Firmicutes can digest fiber and cellulose and are therefore essential for ruminant fermentation [22]. Other significant phyla in the duodenum of the helminth-resistant sheep were Chloroflexi and Elusimicrobia. The Chloroflexi is a complex and diverse group that includes anoxygenic photoautotrophs, aerobic chemoheterotrophs, and thermophilic and anaerobic organisms [23], many of which have been identified in environments as diverse as the human oral cavity, deep-sea sponges, and the sheep rumen [24, 25]. The Elusimicrobia actually contains a single class, the Endomicrobia, that includes numerous members found in the gut of termites and cockroaches, as well as the bovine rumen [26]. Despite being present in the rumen, there is little information about their roles in the ruminant duodenum. 
At genus level, 11 microorganisms were over-represented in the helminth-resistant group. Some of them have recently been taxonomically assigned, including Aminipila, Flexilinea, Lachnoclostridium, and Saccharofermentans. In brief, Aminipila, a novel genus isolated from cattle waste, has been associated with the degradation of L-arginine, L-lysine and L-serine, and the production of short-chain fatty acids, particularly acetate and butyrate [27]. The genus Flexilinea, first reported in Holstein cows that were challenged with a live yeast supplement [28], is strictly anaerobic, requires yeast extract to grow, and ferments mainly carbohydrates [29]. Interestingly, yeasts in the rumen have been shown to improve microbial establishment and the regulation of ruminal $\mathrm{pH}$ [30]. Lachnoclostridium, a novel genus, includes a number of new species identified in the human gut in relation to colorectal tumorigenesis [31], but there is currently no information about their function in the sheep GIT. The novel genus Saccharofermentans, also dominant in the helminth-resistant group, is a specialist in fermentating sugar to produce acetic acid, lactate and fumarate, but cannot degrade cellulose [32]. This genus has recently been identified in the rumen fluid of Chahaer lambs [33]. Among the remaining bacteria associated with the helminth-resistant sheep, are genera that ferment mainly carbohydrates to produce butyrate, propionate and acetate [34-36]: Pseudobutyrivibrio and Succiniclasticum, previously identified in the cow rumen, and Elusimicrobium that was previously identified in the termite gut. Prevotella spp. also degrade protein and carbohydrates and they proliferate following infection by $\mathrm{H}$. contortus and T. circumcincta in small ruminants $[14,37,38]$. These observations align with the increases in the abundance of this genus in helminth-resistant sheep in the present study. The changes in protein absorption included in the pathophysiological responses to helminth infection could elicit an increase in the abundance of Prevotella spp. [39]. In humans, this genus has been found in people consuming strongly plant-based diets as well as those with chronic inflammatory diseases [40].

Bacterial abundance varied with GIT section, and substantial differences were observed among rumenabomasum, small intestine and large intestine. Most common were: Eubacterium, a genus that includes a wide spectrum of species [41]; Oscillibacter, an abundant genus in the faeces of free-grazing sheep (although with low values in the jejunum and ileum) that is linked to the production of butyric acid and alpha-linolenic acid [42]; and Ruminococcus, a genus of cellulose degraders found in various species. These three genera belong to the Firmicutes phyla and most of them can decompose fibre and cellulose [22].

The bacterial populations that we identified as being promoted by helminth infiection are prominent in carbohydrate fermentation in the duodenum of helminth-resistant sheep. Our view is that worm-resistant sheep develop a compensatory mechanism in response to GIT parasites involving a marked disruption of the microbial flora [14]. Bringing all of these observations together, it appears that a high parasite load increases protein loss and carbohydrate degradation at the site of helminth infection.

\section{Conclusions}

The helminth-resistant ewes and rams used for this investigation represent a unique animal resource in the world and thus the microbiome associated with this particular group is critical for control strategies. 
Every GIT section supports a particular bacterial composition leading to inter-sectoral differences among the various communities. In the helminth-resistant sheep, the microbial populations in the duodenum show major bacterial diversity and richness. Helminth-resistant sheep creates a different environment in the duodenum, which make it particularly suitable for certain microbes to thrive. This diverse microbial population consist largely of carbohydrate fermenting organisms. Our observations lead us to propose that the production of short-chain fatty acids, particularly butyrate acid, plays a major role in reducing the parasite burden in worm-resistant sheep.

\section{Methods}

\section{Animals and experimental design}

The Merino sheep used in this experiment were drawn from two flocks: i) the Rylington flock that had been selected for low faecal egg count (FEC) since 1988 [11]; and ii) the 'breech strike' flock that had been established in 2006 and selected for resistance to fly-strike [43], but with no selection for low FEC. Both flocks contain animals that have high potential for genetic resistance and susceptibility to natural helminth infection. It is important to note that these selection lines were not independent because sires had been used across the lines based on their breeding values for the trait of interest. In addition, the Rylington and Breech Strike lines had been run and managed together for the 10 years leading up to the present 2017 study. Therefore, the experimental sheep were genetically linked and also belonged to the same management groups.

This experiment was performed at the Katanning Research Station of the Department of Primary Industries and Regional Development (DPIRD) in Western Australia. It is located in a winter rainfall region with warm dry summers and cold wet winters. The most common and important worm species in this environment are Teladorsagia circumcincta and Trichostrongylus colubriformis, which can cause problems during winter, spring up to early summer.

A total of 986 lambs, born in July and August 2016, were weaned in November 2016, faecal sampled and administered a broad-spectrum oral anthelminthic (Monepantel; $1 \mathrm{~mL} / 10 \mathrm{~kg}$ body weight). From weaning until February 2017, ram and ewe lambs were located separately into two equal-size fields a similar stocking rate (about 10 sheep/hectare) up to September 2017. The pasture composition of the two fields during winter and spring was similar - primarily Trifolium subterraneum, Trifolium repens, Trifolium glomeratum, and Trifolium michelianum.

At weaning, FEC data had been collected for all lambs and, along with the completed pedigrees and the FEC data from previous generations, were submitted to the Australian national genetic evaluation scheme for sheep, Sheep Genetics (www.sheepgenetics.org.au), to obtain estimates of the Australian Standard Breeding Values (ASBVs) of the trait. The ASBVs were then used to identify extreme genotypes: high FEC (ASBV 0 to 100), low FEC (ASBV 0 to - 100). One hundred males and 100 females were selected on the basis of these ASBVclasses. During the experimental period, the sheep received oaten hay ad libitum plus 
a barley-lupin mixed grain supplement (500 g per day per sheep) and the FEC scores were recorded monthly (Table S1).

In September 2017, 18 high FEC and 20 low FEC sheep were sacrificed. At 24 hours prior to the procedure, the 38 animals were all confirmed to be in good health and were placed individually into sanitized pens with ad libitum access to water. After death, the gut was immediately removed and luminal samples were collected from eight GIT segments (rumen, abomasum, duodenum, jejunum, ileum, caecum, and colon). Faecal material was also sampled. All samples were stored at $-80^{\circ} \mathrm{C}$. The luminal content of the 10 sheep with the lowest FEC and 10 sheep with the highest FEC were identified and analysed for the experiment.

\section{DNA extraction}

DNA was extracted using the QIAamp® Fast DNA Stool Mini kit (Qiagen, Germany) with substantial modifications. In brief: $1 \mathrm{~mL}$ of InhibitEX buffer was added to $250 \mathrm{mg}$ of luminal sample prior to incubation at $95^{\circ} \mathrm{C}$ for $5 \mathrm{~min}$. The resultant supernatant was transferred to a new tube included $600 \mu \mathrm{L}$ buffer $\mathrm{AL}$ and $25 \mu \mathrm{L}$ of proteinase $\mathrm{K}$ incubated for $1 \mathrm{~h}$ at $70^{\circ} \mathrm{C}$. The cell lysate was thoroughly mixed with one volume of phenol:chloroform:isoamyl alcohol solution (25:24:1) for $1 \mathrm{~min}$ and centrifuged at 10,000 $x g$ for $5 \mathrm{~min}$. After recovering the aqueous phase, the process was repeated. Subsequently, the aqueous phase was transferred into a new $1.5 \mathrm{~mL}$ tube before adding an equal volume of chloroform:isoamyl alcohol solution (24:1). The mixture was vortexed for $1 \mathrm{~min}$ and centrifuged at 10,000 $\mathrm{xg}$ for $5 \mathrm{~min}$. The aqueous phase was again transferred into a new $1.5 \mathrm{~mL}$ tube, after which was added with two volumes of ice-cold $95 \%(\mathrm{v} / \mathrm{v})$ ethanol to precipitate the DNA. The resulting DNA pellet was washed with $70 \%(\mathrm{v} / \mathrm{v})$ ethanol and resuspended in $50 \mu \mathrm{L}$ Tris-EDTA buffer ( $10 \mathrm{mM}$ Tris-HCL, pH 8.0, $1 \mathrm{mM}$ EDTA). DNA integrity was checked on a $1 \%(\mathrm{w} / \mathrm{v})$ agarose gel electrophoresis and the amount of DNA was quantitated using a Nanodrop spectrophotometer.

\section{S rRNA gene library preparation}

The V3-V4 hypervariable region of the T6S rRNA gene was amplified using the primer sets as specified in Illumina's $16 \mathrm{~S}$ metagenomic sequencing library preparation protocol. In the initial round of PCR amplification, the reaction mixture contained $30 \mathrm{ng}$ of input DNA, 2 units of Taq DNA polymerase (New England Biolabs, United States), $10 \mathrm{mM}$ dNTP, $10 \mu \mathrm{M}$ each of the forward and reverse primers, and $1 \mathrm{x}$ standard Taq reaction buffer. The PCR conditions comprised an initial denaturation at $95^{\circ} \mathrm{C}$ for $30 \mathrm{~s}$, followed by 29 amplification cycles comprising denaturation $\left(95^{\circ} \mathrm{C}\right.$ for $\left.30 \mathrm{~s}\right)$, annealing $\left(55^{\circ} \mathrm{C}\right.$ for $\left.40 \mathrm{~s}\right)$, extension $\left(68^{\circ} \mathrm{C}\right.$ for $\left.1 \mathrm{~min}\right)$, and a final extension at $68^{\circ} \mathrm{C}$ for $5 \mathrm{~min}$. PCR amplicons were visualized using gel electrophoresis on a $1.5 \%(\mathrm{w} / \mathrm{v})$ agarose gel. Following purification of PCR products using AMPure XP beads (Beckman Coulter, United States), indexing PCR was performed using Nextera ${ }^{\circledR}$ XT Index kit (Illumina, United States) according to manufacturer's instructions. The libraries were sequenced on an Illumina MiSeq instrument using the $2 \times 300$ bp paired-end v3 chemistry.

\section{Data analysis}


Raw sequencing data were subjected to quality and adapter trimming using the bbduk.sh command available in BBTools (https://jgi.doe.gov/data-and-tools/bbtools/) with the following parameters: qtrim = r; trimq = 20; ktrim = r/ k = 23; mink = 11; tpe; tbo; hdist = 1; and minlen = 200. After merging of overlapping paired-end reads using MeFiT software with default parameters, sequences with less than 400 bp were filtered [44]. The remaining sequences were subjected to de novo unoise clustering at $97 \%$ sequence identity threshold by running the micca otu command in Micca software (version 1.7.2) to obtain operational taxonomic unit (OTU) sequences [45]. Taxonomic classification of each representative OTU sequence was performed using the Bayesian LCA-based taxonomic classification method against the NCBI RefSeq 16S rRNA database [46], where the acceptance of a taxonomic assignment at each level was based on a minimum confidence score of 80 . The OTU table and the taxonomic information are available in Table S4.

Alpha and beta diversities were estimated using microbiomeSeq R package (https://github.com/umerijaz/microbiomeSeq) and QIIME v1.9.1 [47]. Following rarefaction at the sequence depth level of 1722, alpha diversity was analyzed based on species richness and Shannon diversity metrics, and compared between groups using ANOVA with Tukey's Honestly Significant Difference (HSD) post-hoc test. For beta diversity analysis, principal coordinates analysis (PCoA) was performed at the OTU level using the Bray-Curtis measure, and the statistical significance of the distance matrix was tested using PERMANOVA.

\section{Identification of significant taxa}

To identify distinguishing taxa between groups in the duodenum segment, the Wilcoxon rank-sum test was employed, where differences with $p<0.01$ were considered statistically significant.

\section{Abbreviations}

ASBV: Australian Sheep Breeding Value. ANOVA: Analysis of variance. DPIRD: Department of Primary Industries and Regional Development. GIT: gastrointestinal tract. OTU: Operational taxonomic unit. PERMANOVA: Permutational multivariate analysis of variance. PCR: Polymerase chain reaction. PCoA: Principal Coordinates Analysis. FEC: Faecal egg count.

\section{Declarations}

\section{Acknowledgements}

The authors thank Geoff Cox, Nicola Stanwyck and Tyler Loud who managed the research flocks at the Katanning research facility, and also the postgraduate students at the University of Western Australia who assisted with sampling the animals during this experiment.

\section{Authors' contributions}


Conceptualization: GBM and CYT. Computational analysis and data interpretation: EGC and EAP. Funding acquisition: JCG and GBM. Investigation: EAP, JCG, SUH, DGP, SL, BL, NS, and CL. Writing (original draft): EAP and EGC. Writing (review and editing): GBM and JCG. All authors read and approved the final manuscript.

\section{Funding}

EAP received postdoctoral fellowship support (reference number 74160038) by the National Commission for Scientific and Technological Research (Chile). The Department of Primary Industries and Regional Development of Western Australia is thanked for making funds available for this experiment.

\section{Availability of data and material}

The raw sequencing reads generated in this study have been submitted to NCBI Sequence Read Archive (SRA) database under the BioProject accession number PRJNA674764.

\section{Ethics approval and consent to participate}

All animal experimentation was approved by the Animal Ethics Committee of the WA Department of Primary Industry and Rural Development, under the guidelines of the National Health and Medical Research Council's Australian Code of Practice for the Care and Use of Animals for Scientific Purposes (approval no: AEC 17-1-02).

\section{Consent for publication}

Not applicable

\section{Competing interests}

The authors declare that they have no competing interests.

\section{Authors' details}

${ }^{1}$ UWA Institute of Agriculture, The University of Western Australia, Perth 6009, Australia. ${ }^{2}$ The Marshall Centre for Infectious Disease Research and Training, The University of Western Australia, Perth 6009, Australia. ${ }^{3}$ Department of Primary Industries and Regional Development, South Perth 6151, Australia. ${ }^{4}$ Departamento de Produccion Agropecuaria, CTI-Carne-CEBIOR-BIOREN, Universidad de la Frontera, Av. Francisco Salazar 01145, Temuco, Chile. ${ }^{5}$ College of Animal Science and Technology, Nanjing Agricultural University, Nanjing 210095, China.

\section{References}

1. Lane J, Jubb T, Shephard R, Webb-Ware J, Fordyce G. Priority list of endemic diseases for the red meat industries. Meat \& Livestock Australia Limited; 2015. http://www.mla.com.au/Research-and- 
development/Search-RD-reports/RD-report-details/Animal-Health-and-Biosecurity/Priority-list-ofendemic-diseases-for-the-red-meat-industries/2895. Accessed 5 Oct 2020.

2. Hutchinson GW. Nematode Parasites of Small Ruminants, Camelids and Cattle Diagnosis with Emphasis on Anthelmintic Efficacy and Resistance Testing Part 1. Diagnostic Overview. Aust New Zeal Stand Diagnostic Tech Proced Sub-Committee Anim Heal Lab Stand. 2009.

3. Makovcová K, Langrová I, Vadlejch J, Jankovská I, Lytvynets A, Borkovcová M. Linear distribution of nematodes in the gastrointestinal tract of tracer lambs. Parasitol Res. 2008;104(1):123-6. http://doi.org/10.1007/s00436-008-1169-z.

4. Taylor MA, Coop RL, Wall R. Veterinary Parasitology. 4th edition. New Jersey, U.S.A.: Wiley Blackwell; 2015.

5. Ramos F, Marques CB, Reginato CZ, Bräunig P, Osmari V, Fernandes F, et al. Field and Molecular Evaluation of Anthelmintic Resistance of Nematode Populations from Cattle and Sheep Naturally Infected Pastured on Mixed Grazing areas at Rio Grande do Sul, Brazil. Acta Parasitol. 2020;65(1):118-27. http://doi.org/10.2478/s11686-019-00137-6.

6. Santiago-Figueroa I, Lara-Bueno A, González-Garduño R, López-Arellano ME, de la Rosa-Arana JL, Maldonado-Simán E de J. Anthelmintic resistance in hair sheep farms in a sub-humid tropical climate, in the Huasteca Potosina, Mexico. Vet Parasitol Reg Stud Reports. 2019;17:100292. http://doi.org/10.1016/j.vprsr.2019.100292.

7. Lambertz C, Poulopoulou I, Wuthijaree K, Gauly M. Anthelmintic resistance in gastrointestinal nematodes in sheep raised under mountain farming conditions in Northern Italy. Vet Rec Open. 2019;6(1). http://doi.org/10.1136/vetreco-2018-000332.

8. Woolaston RR. Selection of Merino sheep for increased and decreased resistance to Haemonchus contortus: Peri-parturient effects on faecal egg counts. Int J Parasitol. 1992;22(7):947-53. http://doi.org/10.1016/0020-7519(92)90052-M.

9. Bouix J, Krupinski J, Rzepecki R, Nowosad B, Skrzyzala I, Roborzynski M, et al. Genetic resistance to gastrointestinal nematode parasites in polish long-wool sheep. Int J Parasitol. 1998;28(11):1797804. http://doi.org/10.1016/S0020-7519(98)00147-7.

10. Gauly M, Erhardt G. Genetic resistance to gastrointestinal nematode parasites in Rhön sheep following natural infection. Vet Parasitol. 2001;102(3):253-9. http://doi.org/10.1016/S03044017(01)00530-1.

11. Karlsson LJE, Greeff JC. Selection response in fecal worm egg counts in the Rylington Merino parasite resistant flock. Aust J Exp Agric. 2006;46(7):809-11. http://doi.org/10.1071/EA05367.

12. De Cisneros JPJ, Matthews L, Mair C, Stefan T, Stear MJ. The transfer of IgA from mucus to plasma and the implications for diagnosis and control of nematode infections. Parasitology. 2014;141(7):875-9. http://doi.org/10.1017/S0031182013002321.

13. Greer AW, McKenzie JL, McAnulty RW, Huntley JF, McNeilly TN. Immune development and performance characteristics of Romney sheep selected for either resistance or resilience to 
gastrointestinal nematodes. Vet Parasitol. 2018;250:60-7.

http://doi.org/10.1016/j.vetpar.2017.12.013.

14. Mamun MA Al, Sandeman M, Rayment P, Brook-Carter P, Scholes E, Kasinadhuni N, et al. Variation in gut bacterial composition is associated with Haemonchus contortus parasite infection of sheep. Anim Microbiome. 2020;2(1):1-14. http://doi.org/10.1186/s42523-020-0021-3.

15. Besier RB, Love SCJ. Anthelmintic resistance in sheep nematodes in Australia: the need for new approaches. Aust J Exp Agric. 2003;43:1383-91. http://doi.org/10.1071/EA02229.

16. Barker IK, Titchen DA. Gastric dysfunction in sheep infected with Trichostrongylus colubriformis, a nematode inhabiting the small intestine. Int J Parasitol. 1982;12(4):345-56.

http://doi.org/10.1016/0020-7519(82)90038-8.

17. Ransom-Jones E, Jones DL, McCarthy AJ, McDonald JE. The Fibrobacteres: An Important Phylum of Cellulose-Degrading Bacteria. Microbial Ecology. 2012;63(2):267-81. http://doi.org/10.1007/s00248-011-9998-1.

18. Dixon RM, Nolan J V. Studies of the large intestine of sheep. Br J Nutr. 1982;47(2):289-300. http://doi.org/10.1079/bjn19820038.

19. Wang J, Fan H, Han Y, Zhao J, Zhou Z. Characterization of the microbial communities along the gastrointestinal tract of sheep by 454 pyrosequencing analysis. Asian-Australasian J Anim Sci. 2017;30(1):100-10. http://doi.org/10.5713/ajas.16.0166.

20. Zeng Y, Zeng D, Ni X, Zhu H, Jian P, Zhou Y, et al. Microbial community compositions in the gastrointestinal tract of Chinese Mongolian sheep using Illumina MiSeq sequencing revealed high microbial diversity. AMB Express. 2017;7. http://doi.org/10.1186/s13568-017-0378-1.

21. Mamun MAA, Sandeman M, Rayment P, Brook-Carter P, Scholes E, Kasinadhuni N, et al. The composition and stability of the faecal microbiota of Merino sheep. J Appl Microbiol. 2019;128(1):280-91. http://doi.org/10.1111/jam.14468.

22. Evans NJ, Brown JM, Murray RD, Getty B, Birtles RJ, Hart CA, et al. Characterization of Novel Bovine Gastrointestinal Tract Treponema Isolates and Comparison with Bovine Digital Dermatitis Treponemes. Appl Environ Microbiol. 2011;77(1):138-47. http://doi.org/10.1128/AEM.00993-10.

23. Gupta RS. Molecular Markers for Photosynthetic Bacteria and Insights into the Origin and Spread of Photosynthesis. In: Advances in Botanical Research. Academic Press Inc.; 2013. p. 37-66.

24. Castro-Carrera T, Toral PG, Frutos P, McEwan NR, Hervás G, Abecia L, et al. Rumen bacterial community evaluated by 454 pyrosequencing and terminal restriction fragment length polymorphism analyses in dairy sheep fed marine algae. J Dairy Sci. 2014;97(3):1661-9. http://doi.org/10.3168/jds.2013-7243.

25. Sanjeeviraman J. Chloroflexi: The tale of a Bacterium Present in Human and Environmental Habitats. San Jose State University; 2015. http://doi.org/10.31979/etd.a5ab-5k4u.

26. Ohkuma M, Sato T, Noda S, Ui S, Kudo T, Hongoh Y. The candidate phylum 'Termite Group 1' of bacteria: phylogenetic diversity, distribution, and endosymbiont members of various gut flagellated 
protists. FEMS Microbiol Ecol. 2007;60(3):467-76. http://doi.org/10.1111/j.15746941.2007.00311.x.

27. Ueki A, Goto K, Kaku N, Ueki K. Aminipila butyrica gen. Nov., sp. nov., a strictly anaerobic, argininedecomposing bacterium isolated from a methanogenic reactor of cattle waste. Int J Syst Evol Microbiol. 2018;68(1):443-8. http://doi.org/10.1099/ijsem.0.002534.

28. Bach A, López-García A, González-Recio O, Elcoso G, Fàbregas F, Chaucheyras-Durand F, et al. Changes in the rumen and colon microbiota and effects of live yeast dietary supplementation during the transition from the dry period to lactation of dairy cows. J Dairy Sci. 2019;102(7):6180-98. http://doi.org/10.3168/jds.2018-16105.

29. Sun L, Toyonaga M, Ohashi A, Matsuura N, Tourlousse DM, Meng XY, et al. Isolation and characterization of flexilinea flocculi gen. Nov., sp. Nov., a filamentous, anaerobic bacterium belonging to the class anaerolineae in the phylum chloroflexi. Int J Syst Evol Microbiol. 2016;66(2):988-96. http://doi.org/10.1099/ijsem.0.000822.

30. Chaucheyras-Durand F, Walker ND, Bach A. Effects of active dry yeasts on the rumen microbial ecosystem: Past, present and future. Anim Feed Sci Technol. 2008;145(1-4):5-26. http://doi.org/10.1016/j.anifeedsci.2007.04.019.

31. Liang JQ, Li T, Nakatsu G, Chen YX, Yau TO, Chu E, et al. A novel faecal Lachnoclostridium marker for the non-invasive diagnosis of colorectal adenoma and cancer. Gut. 2020;69(7):1248-57. http://doi.org/10.1136/gutjnl-2019-318532.

32. Chen S, Niu L, Zhang Y, Shuangya Chen C. Saccharofermentans acetigenes gen. nov., sp. nov., an anaerobic bacterium isolated from sludge treating brewery wastewater. Int J Syst Evol Microbiol. 2010;60(12):2735-2738. http://doi.org/10.1099/ijs.0.017590-0.

33. Yang $\mathrm{C}$ tao, SI B wen, Diao Q yu, Jin H, Zeng S qin, Tu Y. Rumen fermentation and bacterial communities in weaned Chahaer lambs on diets with different protein levels. J Integr Agric. 2016;15(7):1564-74. http://doi.org/10.1016/S2095-3119(15)61217-5.

34. Van Gylswyk NO, Hippe H, Rainey FA. Pseudobutyrivibrio ruminis gen. nov., sp. nov., a butyrateproducing bacterium from the rumen that closely resembles Butyrivibrio fibrisolvens in phenotype. Int J Syst Bacteriol. 1996;46(2):559-63. http://doi.org/10.1099/00207713-46-2-559.

35. Pitta DW, Pinchak WE, Dowd SE, Osterstock J, Gontcharova V, Youn E, et al. Rumen Bacterial Diversity Dynamics Associated with Changing from Bermudagrass Hay to Grazed Winter Wheat Diets. Microb Ecol. 2010;59(3):511-22. http://doi.org/10.1007/s00248-009-9609-6.

36. Belanche A, Kingston-Smith AH, Griffith GW, Newbold CJ. A Multi-Kingdom Study Reveals the Plasticity of the Rumen Microbiota in Response to a Shift From Non-grazing to Grazing Diets in Sheep. Front Microbiol. 2019;10:122. http://doi.org/10.3389/fmicb.2019.00122.

37. Li RW, Li W, Sun J, Yu P, Baldwin RL, Urban JF. The effect of helminth infection on the microbial composition and structure of the caprine abomasal microbiome. Sci Rep. 2016;6(1):1-10. http://doi.org/10.1038/srep20606. 
38. Cortés A, Wills J, Su X, Hewitt RE, Robertson J, Scotti R, et al. Infection with the sheep gastrointestinal nematode Teladorsagia circumcincta increases luminal pathobionts. Microbiome. 2020;8(1):1-15. http://doi.org/10.1186/s40168-020-00818-9.

39. Wallace RJ. Ruminal Microbial Metabolism of Peptides and Amino Acids. J Nutr. 1996;126(4 Suppl):1326S-1334S. https://academic.oup.com/jn/article-abstract/126/suppl_4/1326S/4724813. Accessed 18 Apr 2020.

40. Ley RE. Prevotella in the gut: choose carefully. Nat Rev Gastroenterol Hepatol. 2016;13(2):69-70. http://doi.org/10.1038/nrgastro.2016.4.

41. Wade WG. The Genus Eubacterium and Related Genera. In: The Prokaryotes. Springer US; 2006. p. 823-35. http://doi.org/10.1007/0-387-30744-3_28.

42. Wang B, Luo Y, Su R, Yao D, Hou Y, Liu C, et al. Impact of feeding regimens on the composition of gut microbiota and metabolite profiles of plasma and feces from Mongolian sheep. J Microbiol. 2020;58(6):472-82. http://doi.org/10.1007/s12275-020-9501-0.

43. Greeff JC, Karlsson LJE, Schlink AC. Identifying indicator traits for breech strike in Merino sheep in a Mediterranean environment. Anim Prod Sci. 2014;54(2):125-40. http://doi.org/10.1071/AN12233.

44. Parikh HI, Koparde VN, Bradley SP, Buck GA, Sheth NU. MeFiT: Merging and filtering tool for illumina paired-end reads for 16S rRNA amplicon sequencing. BMC Bioinformatics. 2016;17(1):491. http://doi.org/10.1186/s12859-016-1358-1.

45. Albanese D, Fontana P, De Filippo C, Cavalieri D, Donati C. MICCA: A complete and accurate software for taxonomic profiling of metagenomic data. Sci Rep. 2015;5(1):1-7. http://doi.org/10.1038/srep09743.

46. Gao X, Lin H, Revanna K, Dong Q. A Bayesian taxonomic classification method for $16 \mathrm{~S}$ rRNA gene sequences with improved species-level accuracy. BMC Bioinformatics. 2017;18(1):1-10. http://doi.org/10.1186/s12859-017-1670-4.

47. Gregory Caporaso J, Kuczynski J, Stombaugh J, Bittinger K, Bushman FD, Costello EK, et al. QIIME allows analysis of high-throughput community sequencing data. Nat Methods. 2010;7(5):335-6. http://doi.org/10.1038/NMETH.F.303.

\section{Figures}




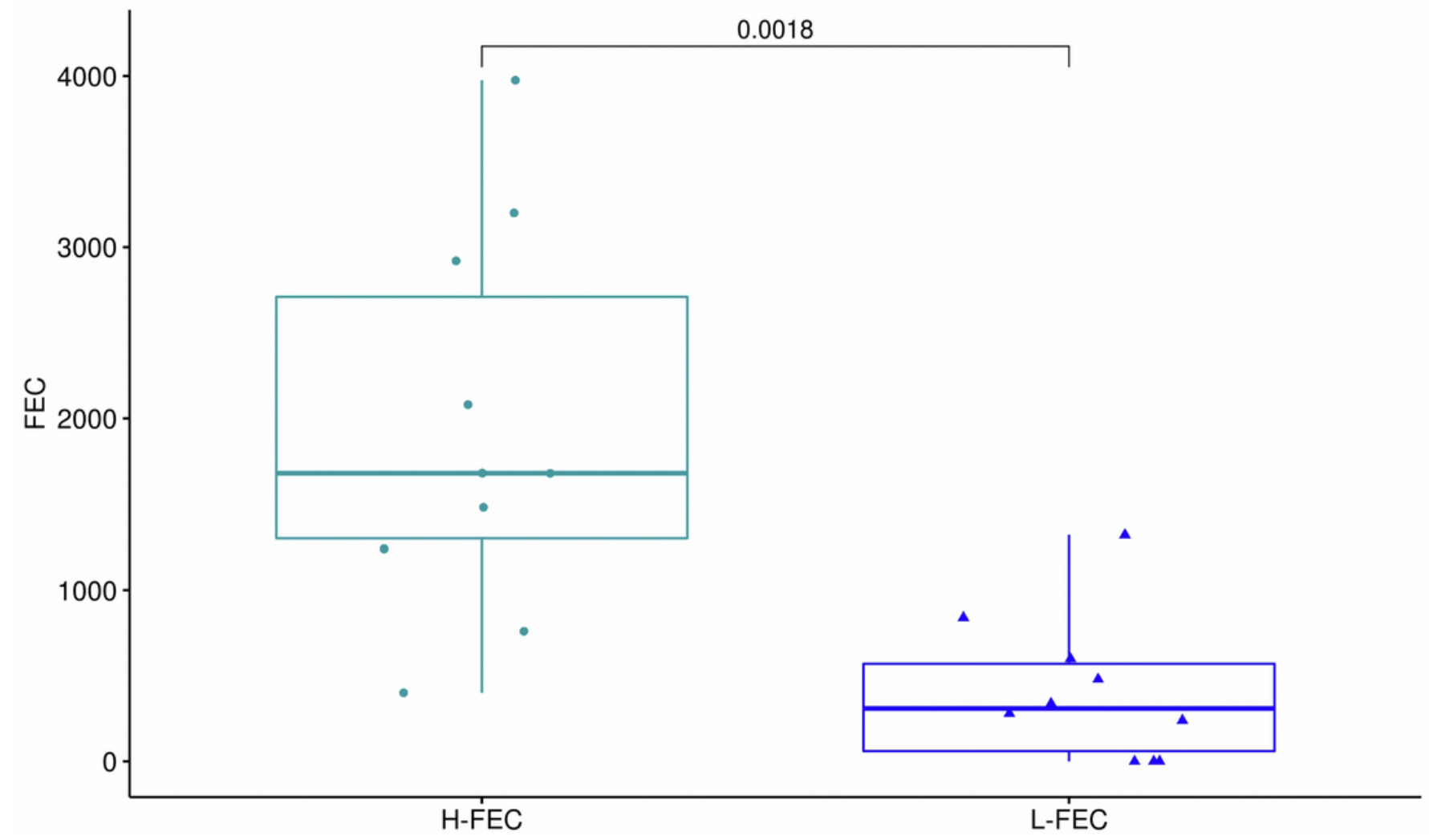

Figure 1

Comparative analysis of High-FEC $(n=10)$ and Low-FEC $(n=10)$ groups. Unpaired boxplot t-test.

A

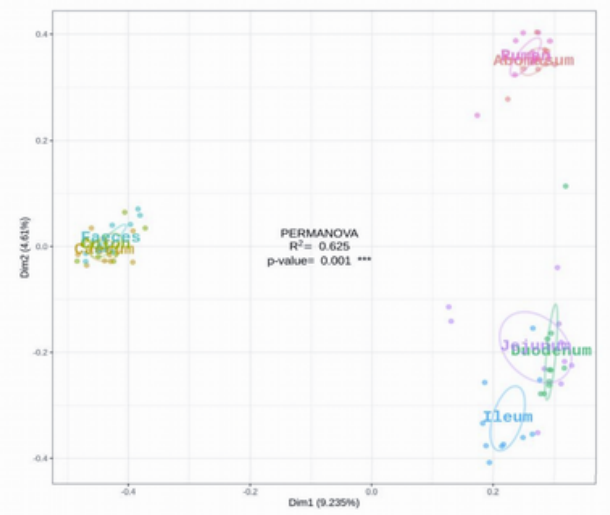

B

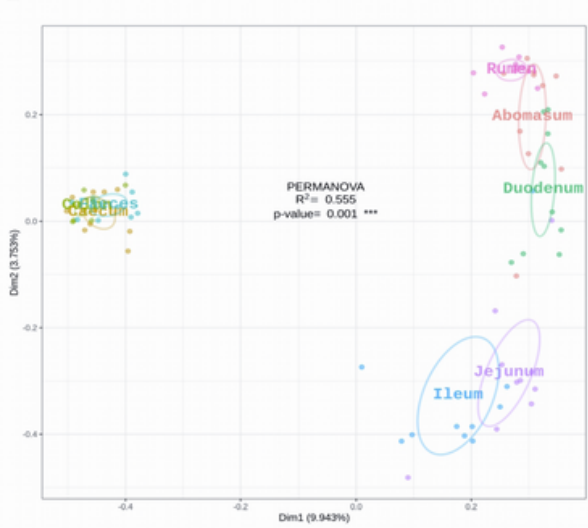

C

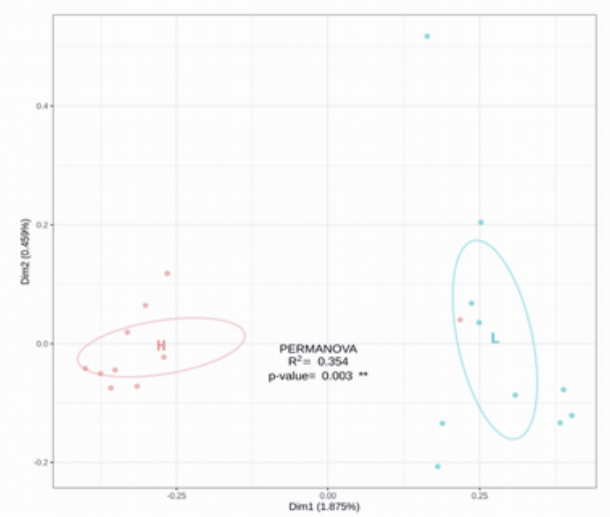

Figure 2

Principal coordinates analysis of the GIT segments. (a) Microbiome clustering in the High-FEC group. (b) Microbiome clustering in the Low-FEC group. (c) Duodenal clustering in the High-FEC and Low-FEC groups. 


\begin{tabular}{|c|c|c|c|c|c|c|c|c|c|c|c|c|c|c|c|c|}
\hline \multirow[b]{2}{*}{ Phylum } & \multicolumn{2}{|c|}{ Rumen } & \multicolumn{2}{|c|}{ Abomasum } & \multicolumn{2}{|c|}{ Duodenum } & \multicolumn{2}{|c|}{ Jejunum } & \multicolumn{2}{|c|}{ Ileum } & \multicolumn{2}{|c|}{ Caecum } & \multicolumn{2}{|c|}{ Colon } & \multicolumn{2}{|c|}{ Faeces } \\
\hline & H-FEC & L-FEC & H-FEC & L-FEC & H-FEC & L-FEC & H-FEC & L-FEC & H-FEC & L-FEC & H-FEC & L-FEC & H-FEC & L-FEC & H-FEC & L-FEC \\
\hline Firmicutes & 100 & 100 & 100 & 100 & 100 & 100 & 100 & 100 & 100 & 100 & 100 & 100 & 100 & 100 & 100 & 100 \\
\hline Bacteroidetes & 100 & 100 & 100 & 90 & 70 & 90 & 90 & 100 & 60 & 60 & 100 & 100 & 100 & 100 & 100 & 100 \\
\hline Proteobacteria & 100 & 100 & 100 & 90 & 50 & 80 & 90 & 70 & 100 & 90 & 100 & 100 & 100 & 100 & 100 & 100 \\
\hline Actinobactería & 60 & 30 & 100 & 80 & 90 & 100 & 90 & 100 & 100 & 90 & 20 & 10 & 30 & 40 & 30 & 40 \\
\hline Synergistetes & 90 & 80 & 90 & 90 & 40 & 70 & 30 & 30 & 10 & 40 & 30 & 30 & 30 & 40 & 30 & 50 \\
\hline Elusimicrobia & 100 & 90 & 90 & 60 & 0 & 80 & 60 & 70 & 70 & 60 & 10 & 30 & 40 & 30 & 40 & 20 \\
\hline Euryarchaeota & 100 & 100 & 50 & 60 & 80 & 70 & 90 & 90 & 60 & 70 & 30 & 0 & 30 & 10 & 20 & 20 \\
\hline Spirochaetes & 20 & 20 & 30 & 30 & 0 & 0 & 30 & 0 & 20 & 0 & 80 & 80 & 100 & 100 & 90 & 80 \\
\hline Vernucomicrobia & 20 & 20 & 10 & 10 & 10 & 0 & 10 & 0 & 20 & 20 & 100 & 100 & 100 & 100 & 100 & 100 \\
\hline \multicolumn{17}{|l|}{ Genus } \\
\hline Anaerotignum & 0 & 0 & 0 & 0 & 0 & 0 & 0 & 0 & 10 & 10 & 100 & 100 & 100 & 90 & 100 & 90 \\
\hline Anaeromassilibacillus & 0 & 0 & 0 & 0 & 0 & 0 & 0 & 0 & 0 & 10 & 100 & 100 & 100 & 100 & 100 & 100 \\
\hline Flavonifractor & 0 & 10 & 0 & 0 & 0 & 0 & 0 & 0 & 0 & 10 & 100 & 100 & 100 & 100 & 100 & 100 \\
\hline Paraprevotella & 0 & 0 & 0 & 0 & 10 & 0 & 0 & 0 & 10 & 10 & 100 & 100 & 100 & 100 & 90 & 100 \\
\hline Mailhella & 0 & 0 & 10 & 10 & 0 & 0 & 0 & 0 & 10 & 20 & 100 & 100 & 100 & 100 & 100 & 100 \\
\hline Alistipes & 0 & 0 & 10 & 10 & 0 & 0 & 10 & 10 & 10 & 10 & 100 & 100 & 100 & 100 & 100 & 100 \\
\hline Bacteroides & 10 & 10 & 10 & 10 & 10 & 10 & 0 & 10 & 20 & 20 & 100 & 100 & 100 & 100 & 100 & 100 \\
\hline Akkermansia & 20 & 20 & 10 & 10 & 10 & 0 & 10 & 0 & 20 & 20 & 100 & 100 & 100 & 100 & 100 & 100 \\
\hline Treponema & 20 & 20 & 30 & 30 & 0 & 0 & 10 & 0 & 0 & 0 & 80 & 80 & 100 & 100 & 90 & 80 \\
\hline Eubacterium & 90 & 100 & 100 & 90 & 100 & 90 & 90 & 90 & 90 & 90 & 100 & 100 & 100 & 100 & 100 & 100 \\
\hline Oscillibacter & 100 & 100 & 100 & 100 & 90 & 90 & 30 & 50 & 40 & 50 & 100 & 100 & 100 & 100 & 100 & 100 \\
\hline Romboutsia & 0 & 30 & 0 & 0 & 10 & 0 & 50 & 60 & 100 & 90 & 80 & 80 & 90 & 80 & 90 & 90 \\
\hline Intestinimonas & 0 & 0 & 0 & 0 & 0 & 0 & 0 & 10 & 0 & 10 & 80 & 80 & 90 & 100 & 100 & 100 \\
\hline Ethanoligenens & 100 & 100 & 90 & 70 & 40 & 70 & 0 & 0 & 0 & 20 & 80 & 100 & 90 & 90 & 100 & 90 \\
\hline Paeniclostridium & 30 & 20 & 10 & 0 & 10 & 0 & 50 & 60 & 100 & 90 & 60 & 80 & 80 & 70 & 80 & 40 \\
\hline Desulfovibrio & 70 & 60 & 90 & 90 & 20 & 50 & 60 & 40 & 50 & 70 & 70 & 60 & 80 & 80 & 80 & 60 \\
\hline Campylobacter & 90 & 100 & 100 & 60 & 0 & 50 & 20 & 50 & 30 & 50 & 60 & 50 & 80 & 50 & 80 & 60 \\
\hline Ruminococcus & 100 & 100 & 100 & 100 & 100 & 100 & 100 & 100 & 90 & 100 & 40 & 80 & 70 & 70 & 80 & 60 \\
\hline Mogibacterium & 80 & 80 & 70 & 100 & 100 & 100 & 80 & 90 & 90 & 70 & 20 & 10 & 60 & 10 & 60 & 50 \\
\hline Saccharofermentans & 100 & 100 & 100 & 100 & 40 & 100 & 90 & 80 & 80 & 80 & 40 & 60 & 60 & 80 & 90 & 90 \\
\hline Succiniclasticum & 100 & 100 & 100 & 100 & 40 & 90 & 40 & 40 & 50 & 60 & 60 & 70 & 60 & 100 & 60 & 90 \\
\hline Blautia & 30 & 50 & 30 & 30 & 40 & 80 & 80 & 90 & 50 & 80 & 20 & 10 & 40 & 10 & 60 & 40 \\
\hline Flintibacter & 90 & 80 & 90 & 100 & 90 & 100 & 60 & 80 & 60 & 60 & 20 & 40 & 40 & 10 & 40 & 30 \\
\hline Elusimicrobium & 100 & 90 & 90 & 60 & 0 & 80 & 60 & 70 & 70 & 60 & 10 & 30 & 40 & 30 & 40 & 20 \\
\hline$P_{\text {seudobutyrivibrio }}$ & 100 & 100 & 100 & 100 & 20 & 90 & 20 & 30 & 10 & 20 & 60 & 50 & 40 & 30 & 50 & 40 \\
\hline Prevotella & 100 & 100 & 100 & 80 & 20 & 90 & 20 & 50 & 10 & 20 & 20 & 70 & 40 & 40 & 60 & 60 \\
\hline Methanobrevibacter & 100 & 100 & 50 & 60 & 80 & 70 & 90 & 90 & 60 & 70 & 30 & 0 & 30 & 10 & 20 & 20 \\
\hline Clostridium & 0 & 0 & 60 & 40 & 10 & 50 & 60 & 60 & 100 & 90 & 40 & 40 & 30 & 10 & 10 & 30 \\
\hline Butyrivibrio & 100 & 100 & 100 & 100 & 80 & 100 & 40 & 50 & 40 & 60 & 40 & 70 & 30 & 50 & 40 & 60 \\
\hline Olsenella & 40 & 20 & 20 & 30 & 60 & 50 & 70 & 80 & 100 & 90 & 0 & 0 & 20 & 20 & 20 & 30 \\
\hline Lachnoclostridium & 90 & 70 & 90 & 90 & 10 & 90 & 0 & 20 & 20 & 40 & 0 & 30 & 20 & 10 & 20 & 10 \\
\hline Solobacterium & 0 & 20 & 10 & 50 & 90 & 90 & 70 & 80 & 30 & 60 & 10 & 0 & 10 & 0 & 0 & 10 \\
\hline Raoultibacter & 0 & 20 & 10 & 20 & 40 & 40 & 80 & 80 & 30 & 60 & 0 & 0 & 10 & 0 & 0 & 20 \\
\hline Moryella & 80 & 90 & 90 & 90 & 20 & 80 & 0 & 20 & 30 & 30 & 10 & 30 & 10 & 40 & 20 & 40 \\
\hline Stomatobaculum & 90 & 80 & 100 & 90 & 10 & 60 & 10 & 10 & 20 & 10 & 0 & 0 & 0 & 0 & 0 & 0 \\
\hline Aminipila & 80 & 70 & 100 & 80 & 20 & 100 & 50 & 50 & 30 & 40 & 0 & 10 & 0 & 0 & 0 & 10 \\
\hline
\end{tabular}

Figure 3

Heatmap of the bacterial distribution across GIT sections at phylum and genus level, for the High-FEC and Low-FEC groups. 


\begin{tabular}{|c|c|c|c|c|c|c|c|c|c|c|c|c|c|c|c|c|}
\hline \multirow[b]{2}{*}{ Phylum } & \multicolumn{2}{|c|}{ Rumen } & \multicolumn{2}{|c|}{ Abomasum } & \multicolumn{2}{|c|}{ Duodenum } & \multicolumn{2}{|c|}{ Jejunum } & \multicolumn{2}{|c|}{ Ileum } & \multicolumn{2}{|c|}{ Caecum } & \multicolumn{2}{|c|}{ Colon } & \multicolumn{2}{|c|}{ Faeces } \\
\hline & H-FEC & L-FEC & H-FEC & L-FEC & H-FEC & L-FEC & H-FEC & L-FEC & H-FEC & L-FEC & H-FEC & L-FEC & H-FEC & L-FEC & H-FEC & L-FEC \\
\hline Spirochaetes & 0 & 0 & 0 & 0 & 0 & 0 & 0 & 0 & 0 & 0 & 0.2 & 0.15 & 0.12 & 0.23 & 0.35 & 0.29 \\
\hline Verrucomicrobia & 0 & 0 & 0 & 0 & 0 & 0 & 0 & 0 & 0 & 0 & 10.1 & 16.7 & 10.19 & 18.79 & 5.84 & 7.9 \\
\hline Actinobacteria & 0.06 & 0 & 10.37 & 0.17 & 0.55 & 3.57 & 1.68 & 0.52 & 0.29 & 0.75 & 0 & 0 & 0 & 0 & 0 & 0 \\
\hline Synergistetes & 0.26 & 0.23 & 0.12 & 0.12 & 0 & 0.12 & 0 & 0 & 0 & 0 & 0 & 0 & 0 & 0 & 0 & 0.03 \\
\hline Elusimicrobia & 0.35 & 0.17 & 0.23 & 0.12 & 0 & 0.09 & 0.12 & 0.15 & 0.12 & 0.06 & 0 & 0 & 0 & 0 & 0 & 0 \\
\hline Proteobacteria & 0.49 & 0.38 & 0.64 & 0.35 & 0.03 & 0.23 & 9.73 & 0.96 & 57.58 & 0.67 & 2 & 0.93 & 2 & 0.81 & 1.95 & 0.96 \\
\hline Euryarchaeota & 0.55 & 0.23 & 0.03 & 0.06 & 0.06 & 0.06 & 0.38 & 0.64 & 0.12 & 0.17 & 0 & 0 & 0 & 0 & 0 & 0 \\
\hline Bacteroidetes & 3.14 & 6.01 & 1.57 & 1.54 & 0.09 & 0.44 & 0.32 & 0.29 & 0.12 & 0.09 & 12.72 & 13.47 & 7.35 & 11.59 & 7.26 & 9.73 \\
\hline Firmicutes & 41.46 & 45.67 & 49.68 & 53.69 & 24.19 & 62.57 & 41.64 & 44.08 & 36.35 & 66.84 & 45.64 & 39.55 & 50.75 & 36.38 & 57.38 & 42.28 \\
\hline \multicolumn{17}{|l|}{ Genus } \\
\hline Akkermansia & 0 & 0 & 0 & 0 & 0 & 0 & 0 & 0 & 0 & 0 & 10.1 & 16.7 & 10.19 & 18.79 & 5.84 & 7.9 \\
\hline Alistipes & 0 & 0 & 0 & 0 & 0 & 0 & 0 & 0 & 0 & 0 & 2.61 & 4.53 & 2.38 & 4.36 & 1.97 & 2.56 \\
\hline Anaeromassilibacillus & 0 & 0 & 0 & 0 & 0 & 0 & 0 & 0 & 0 & 0 & 0.46 & 0.49 & 0.67 & 0.44 & 0.9 & 0.75 \\
\hline Anaerotignum & 0 & 0 & 0 & 0 & 0 & 0 & 0 & 0 & 0 & 0 & 0.49 & 0.61 & 0.29 & 0.26 & 0.44 & 0.26 \\
\hline Bacteroides & 0 & 0 & 0 & 0 & 0 & 0 & 0 & 0 & 0 & 0 & 8.62 & 5.98 & 3.66 & 5.34 & 4.41 & 4.27 \\
\hline Blautia & 0 & 0.03 & 0 & 0 & 0 & 0.06 & 0.2 & 0.23 & 0.03 & 0.32 & 0 & 0 & 0 & 0 & 0.06 & 0 \\
\hline Clostridium & 0 & 0 & 0.38 & 0 & 0 & 0.38 & 1.89 & 0.06 & 1.95 & 0.93 & 0 & 0 & 0 & 0 & 0 & 0 \\
\hline Flavonifractor & 0 & 0 & 0 & 0 & 0 & 0 & 0 & 0 & 0 & 0 & 0.67 & 1.02 & 0.61 & 0.35 & 0.9 & 0.87 \\
\hline Intestinimonas & 0 & 0 & 0 & 0 & 0 & 0 & 0 & 0 & 0 & 0 & 0.35 & 0.32 & 0.55 & 0.44 & 0.61 & 0.41 \\
\hline Mailhella & 0 & 0 & 0 & 0 & 0 & 0 & 0 & 0 & 0 & 0 & 0.75 & 0.55 & 0.7 & 0.73 & 1.02 & 0.52 \\
\hline Olsenella & 0 & 0 & 0 & 0 & 0.06 & 0.03 & 0.49 & 0.23 & 0.2 & 0.41 & 0 & 0 & 0 & 0 & 0 & 0 \\
\hline Paeniclostridium & 0 & 0 & 0 & 0 & 0 & 0 & 0.03 & 0.12 & 7.98 & 10.98 & 0.15 & 0.15 & 0.06 & 0.09 & 0.12 & 0 \\
\hline Paraprevotella & 0 & 0 & 0 & 0 & 0 & 0 & 0 & 0 & 0 & 0 & 0.81 & 0.78 & 0.41 & 0.52 & 0.38 & 0.41 \\
\hline Raoultibacter & 0 & 0 & 0 & 0 & 0 & 0 & 0.17 & 0.17 & 0 & 0.06 & 0 & 0 & 0 & 0 & 0 & 0 \\
\hline Romboutsia & 0 & 0 & 0 & 0 & 0 & 0 & 0.12 & 0.41 & 8.91 & 9.49 & 0.09 & 0.15 & 0.15 & 0.12 & 0.23 & 0.17 \\
\hline Solobacterium & 0 & 0 & 0 & 0.03 & 0.67 & 0.09 & 0.26 & 0.55 & 0 & 0.09 & 0 & 0 & 0 & 0 & 0 & 0 \\
\hline Treponema & 0 & 0 & 0 & 0 & 0 & 0 & 0 & 0 & 0 & 0 & 0.2 & 0.15 & 0.12 & 0.23 & 0.35 & 0.29 \\
\hline Lachnoclostridium & 0.06 & 0.12 & 0.17 & 0.15 & 0 & 0.26 & 0 & 0 & 0 & 0 & 0 & 0 & 0 & 0 & 0 & 0 \\
\hline Mogibacterium & 0.09 & 0.12 & 0.12 & 0.23 & 2.5 & 0.73 & 0.87 & 0.67 & 0.12 & 0.52 & 0 & 0 & 0.06 & 0 & 0.06 & 0.03 \\
\hline Moryella & 0.09 & 0.17 & 0.12 & 0.2 & 0 & 0.29 & 0 & 0 & 0 & 0 & 0 & 0 & 0 & 0 & 0 & 0 \\
\hline Aminipila & 0.12 & 0.12 & 0.41 & 0.38 & 0 & 1.22 & 0.03 & 0.03 & 0 & 0 & 0 & 0 & 0 & 0 & 0 & 0 \\
\hline Desulfovibrio & 0.12 & 0.06 & 0.12 & 0.15 & 0 & 0.03 & 0.06 & 0 & 0.03 & 0.12 & 0.17 & 0.06 & 0.29 & 0.06 & 0.17 & 0.15 \\
\hline Eubacterium & 0.2 & 0.2 & 0.29 & 0.23 & 0.75 & 0.49 & 0.58 & 0.84 & 0.15 & 0.38 & 1.16 & 1.22 & 1.07 & 1.57 & 2.06 & 1.63 \\
\hline Stomatobaculum & 0.23 & 0.26 & 0.17 & 0.29 & 0 & 0.06 & 0 & 0 & 0 & 0 & 0 & 0 & 0 & 0 & 0 & 0 \\
\hline Campylobacter & 0.32 & 0.2 & 0.15 & 0.09 & 0 & 0.03 & 0 & 0.03 & 0 & 0.06 & 0.17 & 0.03 & 0.12 & 0.03 & 0.26 & 0.06 \\
\hline Flintibacter & 0.32 & 0.06 & 0.61 & 0.32 & 0.17 & 1.89 & 0.09 & 0.23 & 0.06 & 0.09 & 0 & 0 & 0 & 0 & 0 & 0 \\
\hline Elusimicrobium & 0.35 & 0.17 & 0.23 & 0.12 & 0 & 0.09 & 0.12 & 0.15 & 0.12 & 0.06 & 0 & 0 & 0 & 0 & 0 & 0 \\
\hline Ethanoligenens & 0.41 & 0.44 & 0.2 & 0.29 & 0 & 0.09 & 0 & 0 & 0 & 0 & 0.35 & 0.46 & 0.49 & 0.49 & 0.38 & 0.64 \\
\hline Methanobrevibacter & 0.55 & 0.23 & 0.03 & 0.06 & 0.06 & 0.06 & 0.38 & 0.64 & 0.12 & 0.17 & 0 & 0 & 0 & 0 & 0 & 0 \\
\hline Saccharofermentans & 1.22 & 1.6 & 1.34 & 1.86 & 0 & 0.78 & 0.44 & 0.23 & 0.17 & 0.55 & 0 & 0.09 & 0.06 & 0.12 & 0.12 & 0.15 \\
\hline Pseudobutyrivibrio & 1.28 & 1.45 & 0.23 & 0.41 & 0 & 0.29 & 0 & 0 & 0 & 0 & 0.06 & 0.03 & 0 & 0 & 0.03 & 0 \\
\hline Ruminococcus & 2.09 & 3.02 & 1.6 & 1.68 & 3.98 & 1.74 & 0.7 & 1.77 & 0.12 & 0.41 & 0 & 0.06 & 0.06 & 0.06 & 0.09 & 0.06 \\
\hline Butyrivibrio & 2.44 & 2.58 & 0.93 & 1.54 & 0.17 & 1.02 & 0 & 0.03 & 0 & 0.06 & 0 & 0.06 & 0 & 0.03 & 0 & 0.09 \\
\hline Succiniclasticum & 2.47 & 2.87 & 0.93 & 1.22 & 0 & 1.57 & 0 & 0 & 0.03 & 0.12 & 0.09 & 0.12 & 0.15 & 0.32 & 0.06 & 0.23 \\
\hline Oscillibacter & 2.56 & 4.47 & 2.06 & 3.75 & 0.15 & 0.96 & 0 & 0.06 & 0 & 0.03 & 4.44 & 4.36 & 4.56 & 4.15 & 4.73 & 4.27 \\
\hline Prevotella & 3.14 & 4.04 & 1.57 & 1.28 & 0 & 0.41 & 0 & 0.03 & 0 & 0 & 0 & 0.15 & 0 & 0 & 0.06 & 0.06 \\
\hline
\end{tabular}

\section{Figure 4}

Heatmap of the relative abundance across GIT sections at phylum and genus level, for the High-FEC and Low-FEC groups.

A

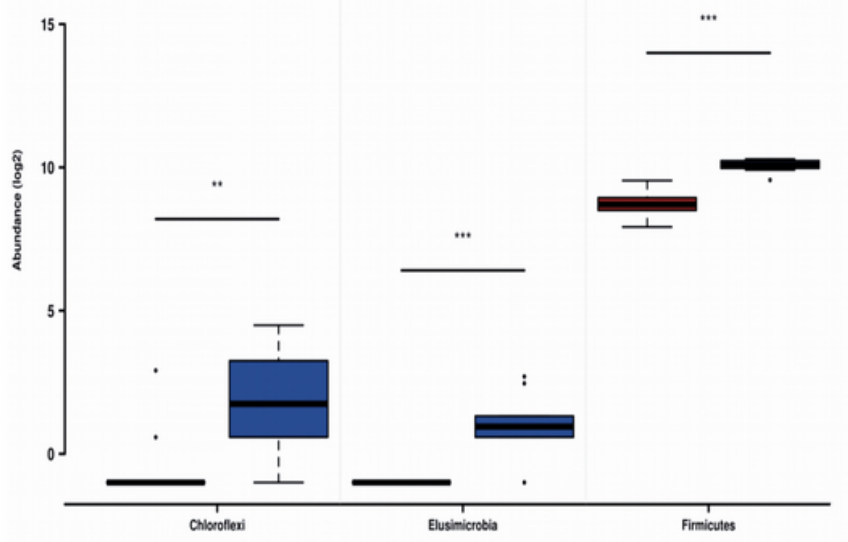

B

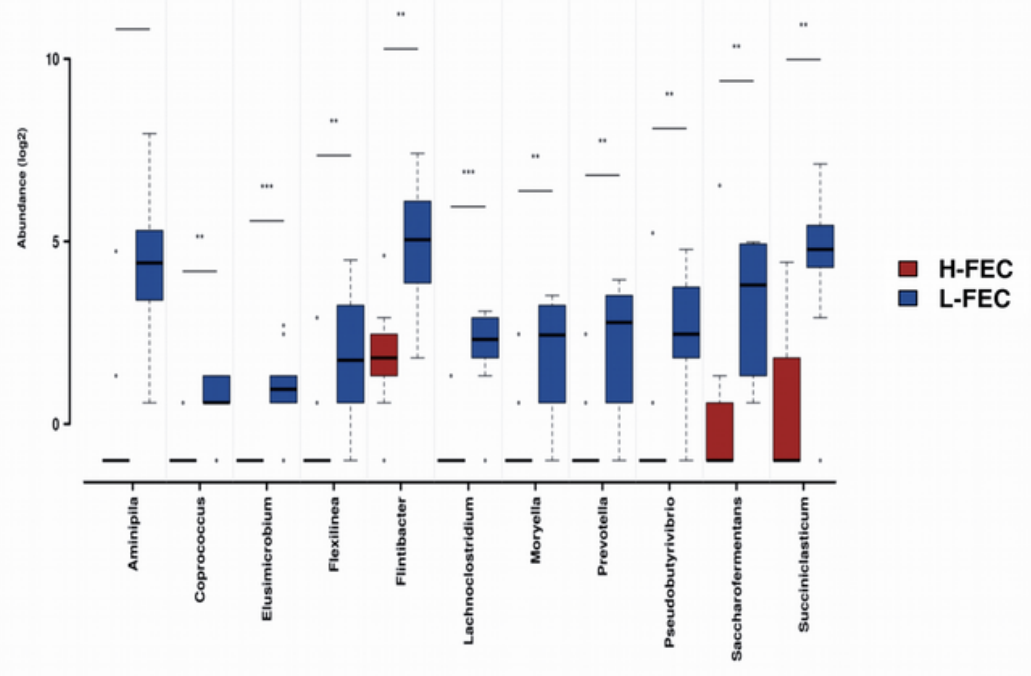

Figure 5 
Distinctive bacterial comparison between the High-FEC and Low-FEC groups. (a) Comparative analysis at phylum level. (b) Comparative analysis at genus level. ${ }^{*} p<0.05,{ }^{*} p<0.01,{ }^{* \star} p<0.001$; Wilcoxon ranksum test.

\section{Supplementary Files}

This is a list of supplementary files associated with this preprint. Click to download.

- TableS1.xIsx

- TableS2.xIsx

- TableS3.xIsx

- TableS4.xIsx 